\title{
High-resolution simulations with COSMO model including TERRA_URB TERRA_URB parameterization for the representation of Urban Heat Islands over South Italy
}

\author{
Edoardo Bucchignani ${ }^{1,2}$ and Paola Mercogliano ${ }^{1,2}$ \\ ${ }^{1}$ Meteorology Lab, CIRA Italian Aerospace Research Center, Capua, 81043, Italy \\ ${ }^{2}$ REMHI division, CMCC Foundation, Capua, 81043 Italy
}

Correspondence: Edoardo Bucchignani (e.bucchignani@cira.it)

Received: 16 October 2019 - Revised: 17 March 2020 - Accepted: 23 March 2020 - Published: 9 April 2020

\begin{abstract}
In this work, some preliminary numerical simulations with the COSMO model including TERRA_URB parameterization have been performed. In particular, this work concerns simulations over a small domain located in southern Italy, in order to test the capabilities of the model in reproducing the main climate features of Urban Heat Islands over this area. Model evaluation has been performed in terms of $2 \mathrm{~m}$ temperature in an urban area and in a rural one, in order to highlight the behaviour of the parameterization in different contexts. Numerical results encourage further investigation and development of urban parameterization in very high-resolution configuration of limited area models and specifically of COSMO, to improve the representation of the maximum daily values of temperature and diurnal cycle especially in urban, but also in rural areas. Furthermore a better parameter tuning is still required for this specific test case.
\end{abstract}

\section{Introduction}

The Urban Heat Island (UHI) effect is one of the most relevant meteorological features of urban environment, since it has substantial implications on human well-being. The increase of built surfaces constitutes the main reason for the formation of UHIs (Milelli, 2016). While natural soil with vegetation uses most of the absorbed radiation in evapotranspiration processes with release of water vapour cooling the surrounding air, paved terrains and buildings tend to absorb a lot of the incident radiation, which is then released as heat. The main characteristic of UHIs is that during the warmest hours of the day, there are small differences between urban and suburban areas; moreover, at sunset the thermal inertia of the city is higher than elsewhere, so there the temperature decreases less than in rural areas, leading to the maximum temperature differences during the night.

In the last years, Limited Area Models have employed very high spatial resolution to improve local forecasts, especially for dangerous convective phenomena and to capture better the urban features. In the same period, a large number of urban land-surface schemes have been developed. They enable the convection permitting atmospheric models to resolve the heterogeneity of cities with applications for heat stress assessment and the development of urban climate adaptation and mitigation strategies.

The main aim of this work is to test the capabilities of the COSMO-LM model with urban parameterization TERRA_URB in reproducing the main climate features of UHIs in southern Italy. TERRA_URB is a bulk parameterization scheme including prescribed Anthropogenic Heat Flux and Impervious Surface Area datasets (Wouters et al., 2015), offering intrinsic representation of the urban physics with modifications of input data, soil module and land atmospheric interactions. Numerical simulations have been performed over a domain centred over Campania region, employing a spatial resolution of $0.009^{\circ}$ (about $1 \mathrm{~km}$ ), for selected test cases.

\section{The Limited area Model COSMO}

COSMO (Steppeler et al., 2003) is the operational weather forecast model of the Consortium for Small-scale Modeling 
(COSMO) originally developed by the German Weather Service (DWD). COSMO is based on the governing equations for a compressible flow. The unresolved scale phenomena are taken into account in a statistical manner through parameterizations. In particular, cities are represented by natural land surface with an increased surface roughness length and a reduced vegetation cover. This representation could not reliably capture the urban physics and associated climatic effects including UHIs. The model version used in the present work includes the urban land use scheme TERRA_URB, which parametrizes the effects of buildings, streets and other man-made impervious surfaces. TERRA_URB implements the Semi-empirical Urban canopy parametrization (SURY) (Wouters et al., 2016), which translates canopy parameters (with 3D information) into bulk parameters while preserving the low computational cost. Bulk schemes are able to simulate the general urban climate features at convection permitting scales. They include the interactions between the excess conversion of incoming radiation into sensible heat, heat accumulation, reduced wind speeds and the anthropogenic heating, resulting in the urban heat island effect. However, they do not explicitly resolve the complex processes depending on the local characteristics and the three-dimensional structure of the canopy, which further modulate the urban climate. The model includes two schemes for simulating the bare soil evaporation: a Biosphere-Atmosphere Transfer Scheme (BATS) (Dickinson, 1984) and a resistance-based formulation (RB) (Schulz and Vogel, 2020).

\section{The computational domain and the test cases considered}

The domain considered, shown in Fig. 1, is centred over Campania and Lazio regions in southern Italy. The two test cases simulated as preliminary investigation of the COSMO version including urban parameterization scheme concerned the following periods: the first one is 8-10 August 2017, since in these days the city of Naples experienced extreme temperature and uncomfortable conditions for the population. The second one is 6-8 June 2019, since in these days a sudden increase of the daily maximum temperature was recorded, from about 27 to about $33^{\circ} \mathrm{C}$. These periods represent a suitable benchmark to test the urban parameterization of COSMO. Initial and boundary conditions are provided by the ECMWF IFS model, characterized by a spatial resolution of $0.075^{\circ}$ (Hortal, 2002).

For each day considered, three simulations have been performed: TERRA_URB switched off (NOURB), TERRA_URB switched on and BATS (URB_bats), TERRA_URB switched on and RB (URB_rb.). A spin-up of $6 \mathrm{~h}$ is assumed. Model evaluation has been performed in terms of $2 \mathrm{~m}$ temperature (T_2m) in an urban area (Naples) and in a rural one (Grazzanise), in order to highlight the behaviour of TERRA_URB in different contexts. The fol-

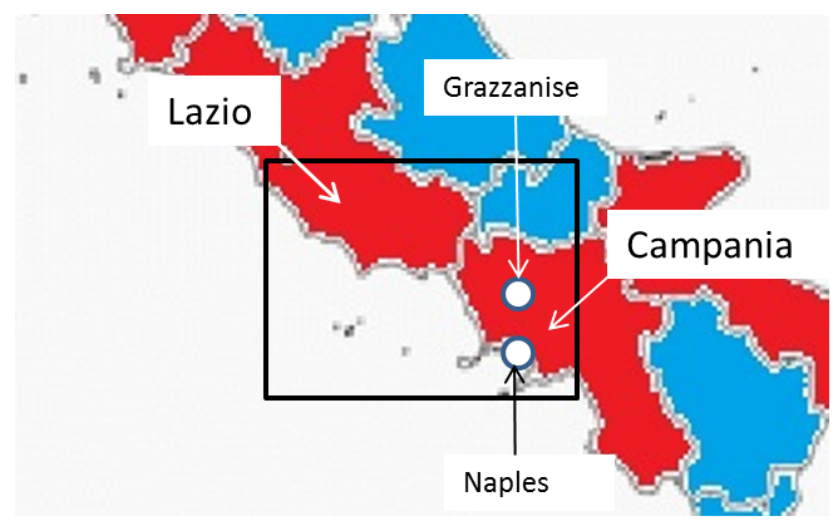

Figure 1. The computational domain with the position of the 2 stations used for the verification (Naples and Grazzanise).

lowing observational data (identified as OBS in the figures) have been considered: hourly time series of $\mathrm{T} \_2 \mathrm{~m}$ provided by the University of Naples, Fuorigrotta quarter (urban area $14.19^{\circ} \mathrm{E}, 40.82^{\circ} \mathrm{N}$ ); maximum and minimum daily values of $\mathrm{T} \_2 \mathrm{~m}$ provided by SCIA ISPRA for the rural station of Grazzanise.

\section{Results}

Figure 2 shows the time series of $\mathrm{T} \_2 \mathrm{~m}$ over the period 8 10 August 2017 at (a) the urban area of Naples and (c) the rural area of Grazzanise. Panel (b) shows the spatial T_2m distribution for 10 August 2017 at 13.00 in a series of points close to Naples location (Naples is located in point 8). AHF in the figure represents the Anthropogenic Heat Flux Distribution, which is used as input by TERRA_URB. In Naples, URB_bats scheme improves the representation of $\mathrm{T} \_2 \mathrm{~m}$ with respect to NOURB, especially the daily minimum values. Anyway, a general underestimation is still evident since the simulated bare soil evaporation by BATS may be too high, thus creating a moist and cold bias, particularly during daytime. URB_rb allows a better behaviour, increasing the average daily $\mathrm{T} \_2 \mathrm{~m}$ of $0.2^{\circ} \mathrm{C}$ and the maximum value of $0.3^{\circ} \mathrm{C}$. In Grazzanise, as expected, URB_bats and URB_rb provide no relevant increases on the maximum T_2m, but undesired increases on the minimum one. Figure 3 shows the time series of T_2m over the period 6-8 June 2019 at (a) the urban area of Naples and (b) the rural area of Grazzanise. In Naples, URB_bats provides higher values of T_2m with respect to NOURB, reducing the average bias. A further small improvement (about $0.1^{\circ}$ ) is achieved with URB_rb. Anyway, a general underestimation is still evident. In Grazzanise, both NOURB and URB_bats simulations underestimate the diurnal cycle and are affected by a cold bias at day time. On the other side, URB_rb improves the representation, especially on the third day. 

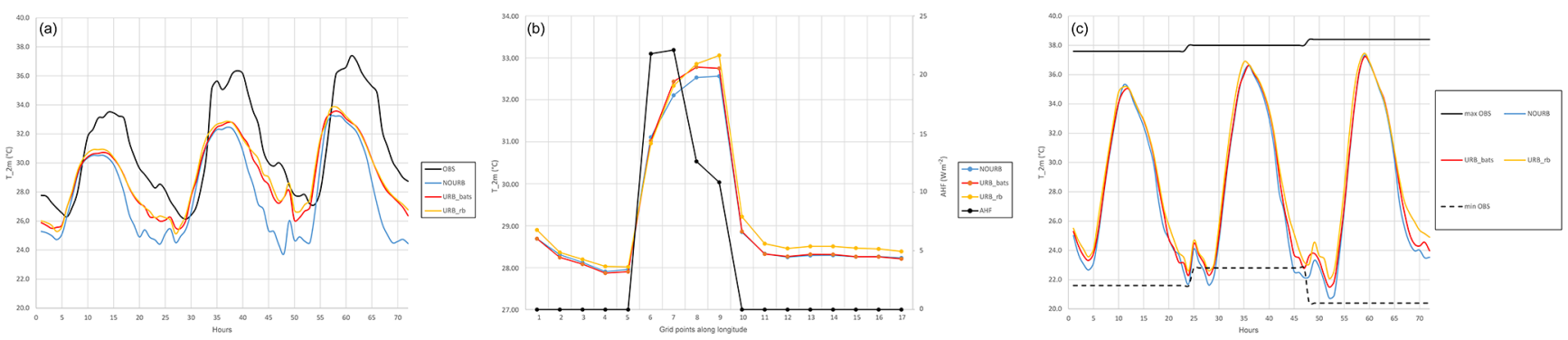

Figure 2. Time series of T_2m over the period 8-10 August 2017 at (a) the urban area of Naples and (c) the rural area of Grazzanise Panel (b) shows the spatial T_2m distribution for Aug 10th 2017 at 13.00 in a series of points close to Naples location.
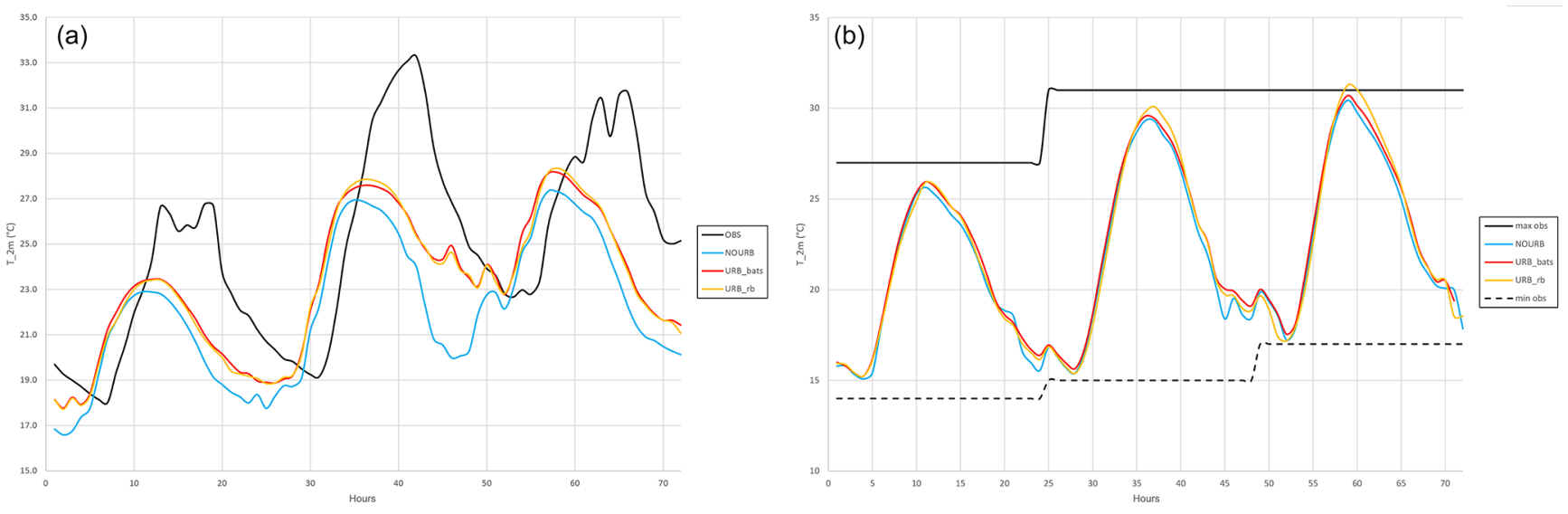

Figure 3. Time series of T_2m over the period 6-8 June 2019 at (a) the urban area of Naples and (b) the rural area of Grazzanise.

\section{Conclusions}

The main aim of the present work was to show some preliminary results obtained testing the capabilities of the COSMO model with urban parameterization TERRA_URB in reproducing the main climate features of UHIs in specific areas of southern Italy. The numerical simulations performed on selected test cases have shown that the usage of TERRA_URB produces a remarkable increase of temperature in urban areas, reducing the model bias, especially when the resistance based scheme is adopted for bare soil evaporation. In rural areas TERRA_URB, as expected, does not produce relevant effects so that the model underestimates the diurnal cycle and is affected by a cold bias at day time. Preliminary tests conducted using a "skin temperature formulation" (Schulz and Vogel, 2020) have shown a reduction of the nocturnal temperatures in rural areas and an increase the UHI intensity (urban-rural temperature difference). It is worth mentioning that the proximity of the sea has an impact on the results, since UHIs are less evident close to the sea. Further investigations with a more accurate tuning of this scheme are required and this will be the topic of future work.
Data availability. The data for this paper are available at the CIRA supercomputing center, Capua (Italy). For data requests please contact Edoardo Bucchignani (e.bucchignani@cira.it).

Author contributions. EB and PM conceived of the presented idea and developed the theory. EB performed the computations. EB wrote the manuscript with support from PM.

Competing interests. The authors declare that they have no conflict of interest.

Special issue statement. This article is part of the special issue "19th EMS Annual Meeting: European Conference for Applied Meteorology and Climatology 2019". It is a result of the EMS Annual Meeting: European Conference for Applied Meteorology and Climatology 2019, Lyngby, Denmark, 9-13 September 2019.

Acknowledgements. The authors acknowledge the University of Naples "Federico II" for providing the observational datasets. The authors want to thank the colleagues of the COSMO Consortium participating to the PT_AEVUS activity. Their collaboration and 
support has been fundamental for the present work. For more information, see the dedicated page on the COSMO web page.

Review statement. This paper was edited by Daniel Reinert and reviewed by two anonymous referees.

\section{References}

Dickinson, R. E.: Modeling evapotranspiration for three dimensional global climate models. Climate processes and Climate sensitivity, Geophys. Monogr, 29, 58-72, 1984.

Hortal, M.: The development and testing of a new two-time-level semi-Lagrangian scheme (SETTLS) in the ECMWF forecast model, Q. J. Roy. Meteorol. Soc., 128, 1671-1687, 2002.

Milelli, M.: Urban heat island effects over Torino, COSMO Newsletter, 16, 3-17, available at: http://www.cosmo-model.org (last access: 8 April 2020), 2016.
Steppeler, J., Doms, G., Schättler, U., Bitzer, H. W., Gassmann, A., Damrath, U., and Gregoric, G.: Meso-gamma scale forecasts using the nonhydrostatic model LM, Meteorol. Atmos. Phys., 82, 75-96, https://doi.org/10.1007/s00703-001-0592-9, 2003.

Wouters, H., Demuzere, M., Ridder, K. D., and van Lipzig, N. P. M.: The impact of impervious water-storage parameterization on urban climate modelling, Urban Clim., 11, 24-50, https://doi.org/10.1016/j.uclim.2014.11.005, 2015.

Wouters, H., Demuzere, M., Blahak, U., Fortuniak, K., Maiheu, B., Camps, J., Tielemans, D., and van Lipzig, N. P. M.: The efficient urban canopy dependency parametrization (SURY) v1.0 for atmospheric modelling: description and application with the COSMO-CLM model for a Belgian summer, Geosci. Model Dev., 9, 3027-3054, https://doi.org/10.5194/gmd-9-3027-2016, 2016.

Schulz, J.-P. and Vogel, G.: Improving the processes in the land surface scheme TERRA: Bare soil evaporation and skin temperature, Atmosphere, in review, 2020. 